\title{
Descriptive Analysis of Functional Behavioral Assessments for Students Who Display Challenging Behaviors
}

\author{
John W. Maag \\ Department of Special Education \& Communication Disorders \\ 202 Barkley Memorial Center, University of Nebraska-Lincoln \\ Lincoln, NE 68583-0732 \\ E-mail: jmaag1@unl.edu
}

\begin{abstract}
Functional behavioral assessment (FBA) has become an integral component in schools for addressing students' challenging behaviors within a school-wide positive behavior interventions and supports (PBIS) approach and under the individuals with disabilities education act (IDEA). There have been literally hundreds of studies conducted on various aspects of FBA including methodologies and participants; and many literature reviews have been undertaken. However, an unanswered question is how necessary and sufficient are complicated, multi-faceted FBA experimental procedures to determine function and an intervention for students who display challenging behaviors? Two previous reviews (Common et al., 2017; Maag, 2018) that focused on students with high incidence disabilities (e.g., learning disabilities, ADHD) or those at-risk had more included studies with students at-risk than with any disability or mental health condition at all. Therefore, the purpose of this review is to describe and analyze the need for educators to perform FBAs prior to developing an individual intensive intervention for students who display challenging behaviors but without a high incidence disability based on information from those two reviews.
\end{abstract}

Keywords: functional behavioral assessment, at-risk, challenging behaviors

DOI: $10.7176 / \mathrm{JEP} / 12-14-01$

Publication date:May $31^{\text {st }} 2021$

\section{Introduction}

Functional behavioral assessment (FBA) refers to a series of heuristic approaches for determining the purpose (i.e., source of environmental reinforcement) students' challenging behaviors serve. An important byproduct of an FBA is the development of a behavior intervention plan (BIP) that addresses the identified functions (Maag \& Katsyiannis, 2006). It is believed that the most effective interventions implemented in school settings are those based on the purpose maladaptive behaviors serve (Ervin et al., 2001). Function-based BIPs may also result in improved generalization and maintenance of treatment gains and enhance the efficacy of existing interventions (Derby et al., 1997; Richman et al., 1997; Taylor \& Miller, 1997). Finally, some researchers suggested that students may favor interventions based on FBAs because they address their everyday desires whose behavior is targeted (Hanely et al., 1997; Tarbox et al., 2009).

There are several circumstances under which FBAs are conducted. Under the 1997 Individuals with Disabilities Education Act (IDEA) amendments, FBAs must be conducted for behaviors that interfere with the learning environment for students with disabilities who are suspended for more than ten schools days, when misconduct results in a manifestation determination, or when weapons, drugs, or serious bodily injury occurs (Katsiyannis \& Maag, 2001). However, within school-wide positive behavior interventions and support (PBIS), FBAs also play a role at the tier 3 level for developing individual intensive interventions. In the case of addressing students' challenging behaviors, PBIS is arranged in three tiers using universal supports in that interventions are provided regardless of the presence or absence of disability. Tier 1, primary prevention, focuses on school-wide systems for all students, staff, and settings. Tier 2, secondary prevention, provides specialized group systems. Tier 3, tertiary prevention, provides intensive individual interventions, typically based on the results of a FBA. Approximately $80 \%$ of students who display inappropriate behaviors respond to tier 1 interventions with another $15 \%$ requiring additional interventions to behave appropriately with the remaining $5 \%$ displaying the most challenging behaviors requiring the intensive individual interventions (Simonsen et al., 2008).

Regardless of within a PBIS system for students displaying challenging behaviors or have high incidence disabilities, FBAs are not without criticisms. There is little consensus as to which techniques should be used to conduct FBAs and they tend to be mired in semantic variations regarding what constitutes required processes (Losinski et al., 2015; Scott et al., 2000; Stage et al., 2006). There are also difficulties conducting and implementing FBAs in school settings, reluctance of teachers to manipulate certain environmental variables for fear of increases in other behaviors, and the inability of teachers to control schedules of reinforcement (Conroy \& Stichter, 2003; Lane, Kalberg, Bruhn, et al., 2009; Stichter et al., 2005; Walker \& Sprague, 1999). Further, the FBA process may not result in reliable, valid, and durable information (Lane, Kalberg, \& Shepcaro, 2009; 
Nelson et al., 1999). Stage and Quiroz (1997) found interventions based on FBAs were less effective than grouporiented contingencies, self-management, and differential reinforcement.

Despite these concerns, there has been - and continues to be - a staggeringly large number of studies examining various aspects of FBA and many systematic reviews have been conducted focusing on various aspects of FBAs and student characteristics. Two of which are germane to the present analysis. Common et al. (2017) tested several recently developed methods for single-case design for 18 studies in which participants either had a high incidence disability or were at risk. Interestingly, of the 27 total participants 17 of them were categorized as "at-risk" but with no other disability label or diagnosis (63\%). The meta-analysis Maag (2018) conducted was more inclusive, searching for studies from 1982 through 2017 and obtained 44 studies examining the effectiveness of FBAs also for students with high incidence disabilities or were "at-risk." There were a total of 90 participants and 35 of them were considered "at-risk" (39\%). Therefore, a substantial number of participants would not fall under the category of high incidence disabilities but rather those who are "at-risk."

Why are so many students involved in these studies "at-risk" but are not identified as having any highincidence (i.e., mild) disabilities? It would seem that part of the eligibility criteria for reviewers of this literature would only be students with high-incidence disabilities rather than "at-risk" - the latter of which would fall under the purview of one or more of the tiers under PBIS. Their behaviors would seemingly be less severe than those with a identified disability - especially those categorized as emotionally or behavioral disordered (EBD). Perhaps part of the answer involves the definition of "at-risk." According to the Psychology Dictionary Professional Reference, the term "at-risk" means someone is vulnerable to an outcome, disorder, or disease (Pam, 2013). For example, someone who smokes is at-risk for developing lung cancer. For students "at-risk" that participate in the studies reviewed by Common et al. (2017) and Maag (2018) could display extreme challenging behaviors commensurate to those engaged in by students with a label of EBD. Or, perhaps students became participants in studies if they were nominated by their teachers as displaying challenging behaviors of which the frequency, duration, or intensity varied depending on the tolerance levels of a given teacher. Consequently, the term "at-risk" is very nebulous and provides no more information than simply saying students who display challenging behaviors but do not have a disability. A simple but functional definition for students with challenging behaviors are simply those who do not respond to traditional forms of discipline such as punitive exclusionary practices (Maag, 2018).

The second question is whether or not students "at-risk" require a FBA in order to determine the function of their maladaptive behavior and, subsequently, provide the information for developing a BIP. Therefore, the purpose of the current analysis is to examine studies with participants only "at-risk" from those reviewed by Common et al. (2017) and Maag (2018) to (a) determine the function their behaviors served, (b) the type of behaviors they displayed that required an FBA, and (c) whether or not the interventions were truly based on the function or simply evidence-based techniques that any teacher would (or should) learn in an applied behavior analysis (i.e., behavior management) course in college. Put another way, when it comes to FBAs for students who display challenging behaviors, how much is too much?

\section{Method}

Unlike systematic reviews that describe eligibility criteria, information sources, search phrases, and interrater reliability, the current descriptive analysis obtained studies from two recent previous reviews by Common et al. (2017) and Maag (2018). The reason was to examine and describe the characteristics of participants who were identified as "at-risk" to determine the necessity and feasibility of conducting FBAs and developing BIPs based on the data for this group. Common and colleagues reviewed 18 studies across 28 participants. The systematic review Maag conducted contained 24 studies and 48 participants. Eight of the 18 studies reviewed by Common and colleagues were omitted from the present review. The reason was because this particular review did not specify objective dependent variables (i.e., target behaviors), preferring instead to use terms such as "off-task," "disruptive behavior," "nonengagement," and "noncompliance." Further, these reviewers only coded for replacement behaviors that were trained but not any specific environmental (e.g., antecedent and consequent) interventions. The remaining 10 studies were mutual to both reviews.

Similarly, the 24 studies in the Maag (2018) review had already been coded (participant characteristics, disability/diagnosis/at-risk, design features, dependent variables, obtained function, and intervention developed from the FBA) and it was not necessary to repeat all of that information here. Rather, Table 1 contains only the authors of the 24 studies, dependent variables (i.e., target behaviors), and interventions since those variables were the prime ones for drawing conclusions of the necessity and sufficiency of conducting FBAs for students at risk.

\section{Results}

Results will first be described in terms of the characteristics of the participants and setting. Second, the types of independent variables and identified functions will be presented. Finally, the interventions used in the studies 
will be summarized.

\subsection{Characteristics of the Participants and Setting}

A total of 48 participants (38 males and 10 females) were included in the 24 studies contained in this descriptive analysis. The youngest participant was five years old (Carter \& Horner, 2009) while the oldest was 15 years of age (Patterson, 2009). The average age for males was eight years and nine years for females. There were four studies for a total of 8 participants that only reported grade level and not age (Christensen et al., 2012; Dejager \& Filter, 2015; Hansen et al., 2014; Lane et al., 2006). Because only studies were included for students "at-risk," all participants were in general education classrooms. Most studies took place during independent practice activities such as paper-and-pencil worksheets typically for the content of mathematics.

\subsection{Dependent Variables and Identified Function}

The majority of studies targeted between three to five dependent variables. The three most commonly targeted behaviors were talking to others, being out of seat/walking around, and not following directions/noncompliance. For the most part, included studies defined target behaviors objectively (e.g., physical aggression, talking out, yelling, arguing, destruction of property, poking peers, kicking, and making animal noises). As could be anticipated given that participants were only "at-risk" (i.e., displaying challenging behaviors), the only two identified functions were positive reinforcement and negative reinforcement. All studies except for one had attention as the positive reinforcement function with one serving as access to tangible objects (e.g., LeGray et al., 2010). The negative reinforcement function was escape from activities/tasks, although there may have been some participants who misbehaved to avoid tasks even though avoidance is technically different from escape conditioning (i.e., negative reinforcement). Although FBA techniques for determining participants' function varied, some used quite elaborate techniques only to find that the identified function was escape from completing a math worksheet or peer and adult attention (e.g., Lane, Smither, et al., 2007).

\subsection{FBA Developed Interventions}

A variety of interventions were developed from the FBAs. Some studies had multi-component interventions while others used one component interventions such as differential reinforcement of other behavior. The most common intervention components were teaching replacement behaviors, contingent attention, extinction, differential negative reinforcement of alternative behavior (DNRA), self-monitoring, and rearranging antecedent cues for appropriate behavior occurring instead of inappropriate behavior. From the descriptions of the interventions, quite elaborate and complicated techniques were used to determine whether problems behaviors displayed by students during academic-related activities were maintained by either attention or escape.

\section{Discussion}

The present article reviewed the literature on the use of FBAs with students in kindergarten through $12^{\text {th }}$ grade who displayed challenging behaviors in their general education classroom. The purpose was to determine the necessity and sufficiency of FBAs for these students during classroom academic lessons or activities. Another purpose was to determine what level of FBA intensity would be required to simply determine students misbehave during paper-and-pencil independent practice activities typically during math lessons was either escape or attention.

Several conclusions can be reached from the current analysis. First, these students with challenging behaviors were mostly elementary school males with a mean age of approximately eight years which would place them in or around the third grade. Second, most of the studies were during routine classroom academic lessons, activities, or tasks. Third, the identified functions, except in one case, were either attention or escape and quite elaborate and complicated techniques were used to make these determinations, sometimes for only one participant. Fourth, the most typical types of behaviors targeted fell under the category of defiance and refusal to follow directions which is easy to see since many students want to escape work that they perceive as too easy or difficult or for attention to distract from a boring task. Fifth, most interventions based on the FBAs were teaching replacement behaviors, positive reinforcement for appropriate behaviors and extinction for inappropriate behaviors, rearranging antecedents, DNRA (e.g., giving students whose behaviors were maintained by escape breaks for task completion), and self-monitoring These are all easy interventions to use with very little consultative guidance.

\subsection{Students with Challenging Behaviors}

Students who display challenging behaviors usually do so during classroom activities, tasks, or lessons. The reason is to either escape a task that is too easy, difficult, or boring (Maag, 2018). In the case of assignments being perceived as boring or irrelevant-whether during group instruction or independent paper-and-pencil worksheets - these students also may misbehave to get attention from peers and/or teachers. This attention is 
stimulating and helps alleviate some of the boredom. Hence, it should come as no surprise that the main functions for their challenging behaviors was either escape or attention. How difficult would it be to determine whether or not a student was misbehaving to escape academic activities? A teacher would know the types of behaviors which are common and reoccurring, have the environment pinpointed (i.e., end of lesson independent practice paper-and-pencil worksheets), and should know the skill proficiency of each student. Further, given that by their very nature schools place demands on students and those with challenging behaviors often find those demands unpleasant, simple behavior management techniques should be in place to offset students displaying challenging behaviors.

\subsection{Determining Function: Overkill?}

Given the nature of the previous statements, it is difficult to understand why extremely complicated and multifaceted FBA methods were used in the studies reviewed simply for determining whether the function for misbehavior was either attention or escape. For example, in a study not reviewed here, Clarke et al. (1995) described using direct observation of antecedent and consequent stimuli, interviews with teachers and other adults, and discussions directly conducted with the students to determine misbehavior functioned as escape. Even more elaborate FBA procedures were used by Lane, Smither, et al. (2007) for one participant to determine the function of his behavior was peer and adult attention: (a) Preliminary Functional Assessment Survey, (b) functional assessment interview with the student, (c) 10 hours of direct observation using an A-B-C approach, (d) teacher completed Motivation Assessment Scale, (e) teacher version of the Social Skills Rating System, and (f) the School Archival Record Search. These data were then analyzed using a functional assessment matrix. It is difficult to imagine school personnel — even school psychologists - would have the expertise and time to engage in all these activities for one student. Consequently, the process would have low social validity - a term that addresses whether a relevant audience (e.g., educators/teachers) find interventions in real-life settings to be acceptable in terms of their goals, methods, personnel, outcomes, and ease of implementation into a teacher's current environment and responsibilities (Schwartz \& Baer, 1991)

Even more streamline procedures such as interviewing teachers and direct observation to obtain the function of escape during individual pencil-paper worksheet activities are time-consuming and perhaps unnecessary. For example, a teacher could conduct a very simple manipulation for a student who is misbehaving during a 10 minute session of writing answers on a math worksheet by telling him that his worksheet was to draw anything he wants (i.e., high-interest activity). If the student draws and does not misbehave during the 10 minutes, escape can be presumed to be the controlling function. Of course, additional assessment would be required (e.g., curriculum-based measurement) to determine what aspects of the math worksheet the student finds unpleasant enough to escape (e.g., work is to easy, hard, or boring), but the initial determination of escape is quite easily and quickly made (Maag \& Kemp, 2003). Conversely, if attention is the suspected function, a teacher can simply ignore a student when he is misbehaving and verbally praise him for displaying appropriate behaviors. It is quite a simple process: extinguish the bad behavior and reinforce the good behavior.

\subsection{What is the Difference Between Function-Based Versus Non-Function Based Interventions?}

In the first paragraph of this articled, several researchers were cited indicating that function-based interventions (i.e., those based on a FBA) were more effective than non-function-based interventions because they may result in improved generalization and maintenance and hypothesized that students would like them better. But is that claim really true? Also earlier I wrote how Stage and Quiroz (1997) found FBA-based intervention were less effective than behavioral techniques such as positive reinforcement being delivered through group-oriented contingencies, self-management techniques (e.g., self-monitoring, self-evaluation, self-reinforcement) and differential reinforcement which is, essentially, withholding reinforcement for inappropriate behavior and administering it for appropriate behavior. Not coincidentally, the "non-function" based techniques of selfmanagement with differential reinforcement were also listed as interventions used in the studies reviewed here as being "function-based." This begs the question: Is there really a difference between function-based and nonfunction-based interventions? The four studies that compared the two types of interventions and concluded that function-based interventions were superior may shed some light on this supposed issue.

Ellingson et al. (2000) examined these two types of interventions on three participants whose inappropriate behaviors were maintained by attention. Function-based interventions included providing participants with noncontingent attention, positive reinforcement for appropriate behavior, and removal of attention when participants engaged in inappropriate behaviors. The non-function-based interventions were based on generating alternative hypotheses of sensory reinforcement and escape: sensory masking for a participant who pounded on her desk, verbal or physical prompt to continuing in the academic task for the second participant, and physically assisting a participant to comply with given instructions. The development and selection of these "non-function-based" interventions is puzzling. The authors took great lengths to determine the correct function for all three participants was attention. Formulating alternative hypotheses that were originally rejected as the identified 
functions just to develop and prove "non-function" based interventions were inferior seems illogical.

Filter and Horner (2009) identified escape as the controlling function for two participants. The nonfunction-based interventions were selected based on their success appearing in published journals. For one participant time-out was implemented contingent upon misbehavior and providing encouragement to the other participant when he exhibited inappropriate behavior. There seems to be two problematic issues. First, if one is going to suppress inappropriate behavior with extinction, then positive reinforcement should also be administered for displaying appropriate behavior. Second, why would one want to provide encouragement (i.e., attention) when a student is misbehaving regardless of what function it served?

The last two studies seemed to incorporate more logical non-function-based interventions. Ingram et al. (2005) had two participants whose problem behaviors function as escape. For the first participant the functionbased and non-function-based interventions were similar in three ways: teacher pre-correcting for appropriate behavior, receiving tokens for displaying appropriate behavior, and self-monitoring on-task behaviors. The only difference in the non-function-based intervention was that the participant did not receive breaks when requesting them. The function-based intervention for the second participant included pre-correcting appropriate behavior, asking him whether he had taken his medication (for ADHD) and, if not, giving him breaks, and self-monitoring and contingently shortening tasks for engaging in appropriate behavior. The non-function-based intervention was asking him if he took his medication and, if not, calling his mother to bring it to school, pre-correcting appropriate behavior, tokens for appropriate behaviors, and self-monitoring attention but did not including giving him breaks nor shortening tasks for appropriate behavior. Three participants were included in the Newcomer and Lewis (2004) study, two whose inappropriate behaviors functioned as escape and the third whose behavior function as adult attention. Non-function-based interventions included providing reinforcement compatible with the school-wide reinforcement system and a dependent group-oriented contingency for one participant, a cueand-prompt procedure for the second participant, and for the last participant teaching her respectful behavior and incorporating cooperative learning strategies.

Several issues become clear from examining these studies. First, in two cases the non-function-based interventions were nonsensical. Second, all the legitimate non-function-based techniques have all been used as function-based interventions in certain instances and vice-versa. Third, function-based interventions such as selfmonitoring and contingent reinforcement have been found to be effective for decades regardless of whether function was considered or not and across academic domains (Hallahan et al., 1979; Reid, 1996). In summary, all evidence-based interventions such as self-monitoring, behavior specific praise, high-probability request sequences (high- $p$ ), differential reinforcement of other behavior (DRO), DNRA (being able to escape the second part of a task contingent upon meeting a performance criterion on the first part), and all forms of delivering positive reinforcement such as token economies, behavioral contracts, group-oriented contingencies such as the Good Behavior Game, and novel applications such as chart moves are all function-based and non-function based interventions. Further, the distinction between whether a student's maladaptive behaviors function as attention or escape may be the least important aspect of choosing an intervention.

\section{Conclusion}

There is no question that FBAs and interventions created from them are an essential component in the education and treatment of individuals with moderate to severe disabilities. However, there is no consensus, and even disagreement, that they are not proven nor maybe even necessary when applied to students not identified as having a disability but nevertheless display challenging behaviors. Further, whether an intervention is considered function-based or non-function-based is more academic than practical. For example, if a student is misbehaving to obtain teacher attention, a "function-based" intervention would be for the teacher to ignore the student when he is misbehaving and provide him with attention when he is behaving appropriately. "Catching students being good" and ignoring them when they are bad is a basic behavior management philosophy — as well as techniquethat all teachers should be following and practicing continuously.

Perhaps the most productive approach would be to begin by implementing a low-intensity intervention (i.e., one with high social validity) while also having class-wide reinforcement contingencies in place such as the Good Behavior Game, using weekly raffles and lotteries, or versions of the compliance matrix (Maag, 2017). One way to minimize students wanting to escape a task or lesson is to make the classroom a more positive and desirable place in which to stay. Class-wide behavior management approaches go a long way for increasing the likelihood of this goal occurring. Hence the reason why future research should focus on the bare minimum FBA techniques required for children who display challenging behaviors. There has been a plethora of research on complicated approaches, but not as much examining the minimal required to be effective and comparing the relative effectiveness between the two.

\section{References}

*Bessett, K. K., \& Wills, H. P. (2007). An example of an elementary school paraprofessional-implemented 
functional analysis and intervention. Behavioral Disorders, 32(3), 192-210. https://doi.org/10.1177\%2F019874290703200304

*Campbell, A., \& Anderson, C. M. (2008). Enhancing effects of check-in/check-out with function-based support. Behavioral Disorders, 33(4), 233-245. https://doi.org/10.1177\%2F019874290803300404

*Carter, D., \& Horner, R. H. (2009). Adding function-based behavioral support to First Step to Success: Integrating individualized and manualized practices. Journal of Positive Behavior Interventions, 11(1), 2234. https://doi.org/10.1177\%2F1098300708319125

*Christensen, L., Renshaw, T. L., Caldarella, P., \& Young, J. R. (2012). Training a general educator to use function-based support for students at risk for behavior disorders. Education, 133(2), 313-335. https://www.ingentaconnect.com/content/prin/ed/2012/00000133/00000002/art00009\#expand/collapse

Clarke, S., Dunlap, G., Foster-Johnson, L., Childs, K. E., Wilson, D., White, R., \& Vera, A. (1995). Improving the conduct of students with behavioral disorders by incorporating student interests into curricular activities. Behavioral Disorders, 20(4), 221-237. https://doi.org/10.1177\%2F019874299502000402

Common, E. A., Lane, K. L., Pustejovsky, J. E., Johnson, A. H., \& Johl, L. E. (2017). Functional assessmentbased interventions for students with or at-risk for high-incidence disabilities: Field testing single-case synthesis methods. Remedial and Special Education, 38(6), 331-352. https://doi.org/10.1177/0741932517693320

Conroy, M. A., \& Stichter, J. (2003). The application of antecedents in the functional assessment process: Existing research, issues, and recommendations. The Journal of Special Education, 37(1), 15-25. https://doi.org/10.1177\%2F00224669030370010201

*Dejager, B. W., \& Filter, K. J. (2015). Effects of prevent-teach-reinforce on academic engagement and disruptive behavior. Journal Applied School Psychology, 31(4), 369-391. https://doi.org/10.1080/15377903.2015.1084966

Derby, K. M., Wacker, D. P., Berg, W., DeRaad, A., Ulrich, S., Asmus, J., Harding, J., Prouty, A., Laffey, P., \& Stoner, E. A. (1997). The long-term effective of functional communication training in home settings. Journal of Applied Behavior Analysis, 30(3), 507-531. https://doi.org/10.1901/jaba.1997.30-507

Ellingson, S. A., Miltenberger, R. G., Stricker, J., Galensky, T. L., \& Garlinghouse, M. (2000). Functional assessment and intervention for challenging behavior in the classroom by general classroom teachers. Journal of Positive Behavior Interventions, 2(2), 85-97. https://doi.org/10.1177\%2F109830070000200202

*Ellis, J., \& Magee, S. K. (1999). Determination of environmental correlates of disruptive classroom behaviour: Integration of functional analysis into public school assessment process. Educational \& Treatment of Children, 22(3), 291-316. https://www.jstor.org/stable/42899576

Ervin, R. A., Radford, P. M., Bertsch, K., Piper, A. L., Ehrhardt, K. E., \& Poling, A. (2001). A descriptive analysis and critique of the empirical literature on school-based functional assessment. School Psychology Review, 30(2), 193-210. https://doi.org/10.1080/02796015.2001.12086109

Filter, K. J., \& Horner, R. H. (2009). Function-based academic interventions for problem behavior. Education and Treatment of Children, 32(1), 1-19. https://doi.org/10.1353/etc.0.0043

*Grandy, S. E., \& Peck, S. M. (1997). The use of functional assessment and self-management with a first grader. Child \& Family Behavior Therapy, 19(2), 29-43. https://doi.org/10.1300/J019v19n02_03

Hallahan, D. P., Lloyd, J. W., Kosiewicz, M. M., Kauffman, J. M., \& Graves, A. W. (1979). Self-monitoring of attention as a treatment for a learning disabled boy's off-task behavior. Learning Disability Quarterly, 2(3), 24-32. https://doi.org/10.2307/1511021

Hanely, G. P., Piazza, C. C., Fisher, W. W., Contrucci, S. A., \& Maglieri, K. A. (1997). Evaluation of client preference for function-based treatment packages. Journal of Applied Behavior Analysis, 30(3), 459-473. https://doi.org/10.1901/jaba.1997.30-459

*Hansen, B. D., Wills, H. P., Kamps, D. M., \& Greenwood, C. R. (2014). Effects of function-based selfmanagement interventions. Journal of Emotional and Behavioral Disorders, 22(3), 149-159. https://doi.org/10.1177\%2F1063426613476345

*Hoff, K. E., Ervin, R. A., \& Friman, P. C. (2005). Refining functional behavioral assessment: Analyzing the separate and combined effects of hypothesized controlling variables during ongoing classroom routines. School Psychology Review, 34(1), 45-57. https://doi.org/10.1080/02796015.2005.12086274

Ingram, K., Lewis-Palmer, T., \& Sugai, G. (2005). Function-based intervention planning: Comparing the effectiveness of FBA function-based and non-function-based intervention plans. Journal of Positive Behavior Interventions, 7(4), 224-236. https://doi.org/10.1177\%2F10983007050070040401

*Kamps, D., Wendland, M., \& Culpepper, M. (2006). Active teacher participation in functional behavior assessment for students with emotional and behavioral disorders risks in general education classrooms. Behavioral Disorders, 31(2), 128-146. https://doi.org/10.1177\%2F019874290603100203

Katsiyannis, A., \& Maag, J. W. (2001). Manifestation determination as a golden fleece. Exceptional Children, 68(1), 85-96. https://doi.org/10.1177/001440290106800105 
Lane, K. L., Kalberg, J. R., Bruhn, A. L., Driscoll, S. A., Wehby, J. H., \& Elliott, S. N. (2009). Assessing social validity of school-wide positive behavior support plans: Evidence for the reliability and structure of the Primary Intervention Rating Scale. School Psychology Review, 38(1), 135-144. https://doi.org/10.1080/02796015.2009.12087854

Lane, K. L., Kalberg, J. R., \& Shepcaro, J. C. (2009). An examination of the evidence base for function-based interventions for students with emotional and/or behavioral disorders attending middle and high school. Exceptional Children, 75(3), 321-340. https://doi.org/10.1177\%2F001440290907500304

*Lane, K. L., Smither, R., Huseman, R., Guffey, J., \& Fox, J. (2007). Function-based intervention to decrease disruptive behavior and increase academic engagement. Journal of Early and Intensive Behavior Interventions, 4(1), 348-364. http://dx.doi.org/10.1037/h0100348

*Lane, K. L., Weisenbach, J. L., Little, A., Phillips, A., \& Wehby, J. (2006). Illustrations of function-based interventions implemented by general education teachers: Building capacity at the school site. Education and Treatment of Children, 29(4), 549-571. https://www.jstor.org/stable/42900553

*Lane, K. L., Weisenbach, J. L., Phillips, A., \& Wehby, J. H. (2007). Designing, implementing, and evaluating function-based interventions using a systematic, feasible approach. Behavioral Disorders, 32(2), 122-139. https://doi.org/10.1177\%2F019874290703200205

*LeGray, M. W., Dufrene, B. A., Sterling-Turner, H., Olmi, D. J., \& Bellone, K. (2010). A comparison of function-based differential reinforcement interventions for children engaging in disruptive classroom behavior. Journal of Behavioral Education, 19, 185-204. https://doi.org/10.1007/s10864-010-9109-2

*Lewis, T. J., \& Sugai, G. (1996). Descriptive and experimental analysis of teacher and peer attention and the use of assessment-based intervention to improve prosocial behavior. Journal of Behavioral Education, 6 , 17-23. https://doi.org/10.1007/BF02110474

Losinski, M., Maag, J. W., Katsiyannis, \& Ryan, J. B. (2015). The use of structural behavioral assessment to develop interventions for secondary students exhibiting challenging behaviors. Education and Treatment of Children, 38(2), 1-16. https://doi.org/10.1353/etc.2015.0006

Maag, J. W. (2017). Behavior management: From theoretical implications to practical applications (3rd ed.). Cengage.

Maag, J. W. (2018). The challenging behavior of teacher resistance. Rethinking Behavior, 2, $23-30$. https://s3.amazonaws.com/pageturnpro2.com/Publications/201810/4255/86925/PDF/131828777269680000 ReThinking_Behavior_Fall_2018.pdf

Maag, J. W., \& Kemp, S. E. (2003). Behavioral intent of power and affiliation: Implications for functional analysis. Remedial and Special Education, 24(1), 57-64. https://doi.org/10.1177\%2F074193250302400106

Maag, J. W., \& Katsiyannis, A. (2006). Behavioral intervention plans: Legal and practical considerations for students with emotional and behavioral disorders. Behavioral Disorders, 31, 348-362. https://doi.org/10.1177/019874290603100403

*Moore, D. W., Anderson, A., \& Kumar, K. (2005). Instructional adaptation in the management of escapemaintained behavior in a classroom. Journal of Positive Behavior Interventions, 7(4), $216-223$. https://doi.org/10.1177\%2F10983007050070040301

Nelson, J. R., Roberts, M. L., Mathur, S. R., \& Rutherford, R. B., Jr. (1999). Has public policy exceeded our knowledge base? A review of the functional behavioral assessment literature. Behavioral Disorders, 24, 169-179. https://doi.org/10.1007/s10864-005-0960-5

*Newcomer, L. L., \& Lewis, T. J. (2004). Functional behavioral assessment: An investigation of assessment reliability and effectiveness of function-based interventions. Journal of Emotional and Behavioral Disorders, 12(3), 168-181. https://doi.org/10.1177\%2F10634266040120030401

*Packenham, M., Shute, R., \& Reid, R. (2004). A truncated functional behavioral assessment procedure for children with disruptive classroom behaviors. Education and Treatment of Children, 27(1), 9-25. https://www.jstor.org/stable/42899781

Pam, N. (2013, April 7). At risk. Psychology dictionary: Professional reference. https://psychologydictionary.org/at-risk/

*Patterson, S. T. (2009). The effects of teacher-student small talk on out-of-seat behavior. Education and Treatment of Children, 32(1), 167-174. https://doi.org/10.1353/etc.0.0048

*Payne, L. D., Scott, T. M., \& Conroy, M. (2007). A school-based examination of the efficacy of function-based intervention. Behavioral Disorders, 32(3), 158-173. https://doi.org/10.1177\%2F019874290703200302

Reid, R. (1996). Research in self-monitoring with students with learning disabilities: The present, the prospects, the pitfalls. Journal of Learning Disabilities, 29(3), 317-331. https://doi.org/10.1177\%2F002221949602900311

Richman, D. M., Berg, W. K., Wacker, D. P., Stephens, T., Rankin, B., \& Kilroy, J. (1997). Using pretreatment and posttreatment assessments to enhance and evaluate existing treatment packages. Journal of Applied Behavior Analysis, 30(4), 709-712. https://doi.org/10.1901/jaba.1997.30-709 
*Sanford, A. K., \& Horner, R. H. (2012). Effects of matching instruction difficulty to reading level for students with escape-maintained problem behavior. Journal of Positive Behavior Interventions, 15(2), 79-89. https://doi.org/10.1177\%2F1098300712449868

Schwarz, I. S., \& Baer, D. M. (1991). Social validity assessments: Is current practice state of the art? Journal of Applied Behavior analysis, 24(2), 189-204. https://doi.org/10.1901/jaba.1991.24-189

Scott, T. M., Meers, D. T., \& Nelson, C. M. (2000). Toward a consensus of functional behavioral assessment for students with mild disabilities in public school contexts: A national survey. Education and Treatment of Children, 23(3), 265-285. https://www.jstor.org/stable/42899619

*Shumate, E., \& Wills, H. (2010). Classroom-based functional analysis and intervention for disruptive and offtask behaviors. Education and Treatment of Children, 33(1), 23-48. https://doi.org/10.1353/etc.0.0088

Simonsen, B., Sugai, G., \& Negron, M. (2008). Schoolwide positive behavior support: Primary systems and practices Teaching Exceptional Children, 40(6), 32-40. https://doi.org/10.1177/004005990804000604

Stage, S. A., Jackson, H. G., Moscovitz, K., Erickson M. J., Thurman, S. O., Jessee, W., \& Olson, E. M. (2006). Using multimethod-multisource functional behavioral assessment for students with behavioral disabilities. School Psychology Review, 35(3), 451-471. https://doi.org/10.1080/02796015.2006.12087978

Stage, S. A., \& Quiroz, D. R. (1997). A meta-analysis of interventions to decrease disruptive classroom behavior in public education settings. School Psychology Review, 26(3), 333-368. https://doi.org/10.1080/02796015.1997.12085871

Stichter, J. P., Hudson, S., \& Sasso, G. M. (2005). The use of structural analysis to identify setting events in applied settings for students with emotional/behavioral disorders. Behavioral Disorders, 30(4), 403-420. https://doi.org/10.1177\%2F019874290503000410

*Storey, K., Lawry, J. R. Ashworth, R., Danko, C. D., \& Strain, P. S. (1994). Functional analysis and intervention for disruptive behaviors of a kindergarten student. Journal of Educational Research, 87(6), 361-370. https://doi.org/10.1080/00220671.1994.9941267

Tarbox, J., Wilke, A. E., Najdowski, A. C., Findel-Pyles, R. S., Balasanyan, S., Caveney, A. C., Chilingaryan, V., King, D. M., Niehoff, S. M., Slease, K., \& Tia, B. (2009). Comparing indirect, descriptive, and experimental functional assessments of challenging behavior in children with autism. Journal of Developmental and Physical Disabilities, 21(6), 493-514. https://doi.org/10.1007/s10882-009-9154-8

Taylor, J. C., \& Miller, M. (1997). When timeout works some of the time: The importance of treatment integrity and functional assessment. School Psychology Quarterly, 12(1), 4-22. https://doi.org/10.1037/h0088943

*Trussell, R. P., Lewis, T. J., \& Raynor, C. (2016). The impact of universal teacher practices and function-based behavior interventions on the rates of problem behaviors among at-risk students. Education and Treatment of Children, 39(3), 261-282. https://doi.org/10.1353/etc.2016.0012

Walker, H. M., \& Sprague, J. R. (1999). Longitudinal research and functional behavioral assessment issues. Behavioral Disorders, 24(4), 335-337. https://doi.org/10.1177\%2F019874299902400407

*indicates study included in the current review. 
Table 1. Characteristics of studies

\begin{tabular}{|c|c|c|}
\hline Study & pendent variables & tervention \\
\hline $\begin{array}{l}\text { 1. Bessett \& Wills } \\
(2007)\end{array}$ & ns; physical & $\begin{array}{l}\text { Replacement behavior (i.e., raise hand for } \\
\text { attention; ask for a break for escape) }\end{array}$ \\
\hline $\begin{array}{l}\text { 2. Campbell \& } \\
\text { Anderson }(2008)\end{array}$ & $\begin{array}{l}\text { Toncompliance, disruption, negative } \\
\text { erbal/physical interaction, out of seat }\end{array}$ & $\begin{array}{l}\text { Check-in/Check-out with contingent morning } \\
\text { lunchroom seating choice }\end{array}$ \\
\hline $\begin{array}{l}\text { 3. Carter \& Horner } \\
\text { (2009) }\end{array}$ & $\begin{array}{l}\text { Talk-outs-disruption; out of seat; } \\
\text { noncompliance-defiance; } \\
\text { confrontation-aggression }\end{array}$ & $\begin{array}{l}\text { First Step to Success; decreased peer attention } \\
\text { for problem behavior, increased peer \& teacher } \\
\text { attention for appropriate behaviors; modifying } \\
\text { work \& preferred activity for escape }\end{array}$ \\
\hline $\begin{array}{l}\text { 4. Christensen et al. } \\
\text { (2012) }\end{array}$ & $\begin{array}{l}\text { g; out of seat; playing } \\
\text { engaging in non-task } \\
\text { s }\end{array}$ & $\begin{array}{l}\text { nent; social skills training; } \\
\text { ht; negative reinforcement }\end{array}$ \\
\hline $\begin{array}{l}\text { 5. Dejager \& Filter } \\
\text { (2015) }\end{array}$ & $\begin{array}{l}\text { uing; blurting out; } \\
\text { lizations }\end{array}$ & $\begin{array}{l}\text { Physical boundary identification \& visual } \\
\text { cues/prompts; replacement behavior training; } \\
\text { noncontingent reinforcement; breaks from } \\
\text { tasks; }\end{array}$ \\
\hline $\begin{array}{l}\text { 6. Ellis \& Magee } \\
\text { (1999) }\end{array}$ & $\begin{array}{l}\text { ng; tantrums; } \\
\text { isal to follow }\end{array}$ & 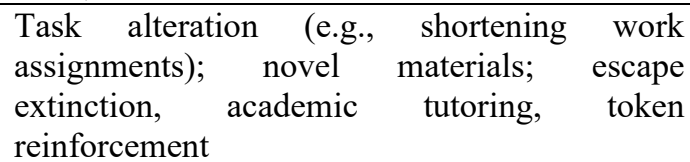 \\
\hline $\begin{array}{l}\text { 7. Grandy \& Peck } \\
\text { (1997) }\end{array}$ & & ng \& adult contingent attention \\
\hline en al. & $\begin{array}{l}\text { others; making noises; } \\
\text { te motor movements }\end{array}$ & ention \\
\hline 9. Hoff & $\begin{array}{l}\text { animal } \\
\text { ng peers; }\end{array}$ & $\begin{array}{l}\text { gent peer } \\
\text { d peers) }\end{array}$ \\
\hline $\begin{array}{l}\text { 10. Kamps et al. } \\
(2006)\end{array}$ & $\begin{array}{l}\text { Out of seat; arguing; taunting, name } \\
\text { calling; noncompliance; aggression } \\
\text { (e.g., hitting, kicking, pushing, } \\
\text { throwing objects) }\end{array}$ & $\mathrm{gg}$ \\
\hline $\begin{array}{l}\text { 11. Lane et al. } \\
(2006)\end{array}$ & eat; blurting & $\begin{array}{l}\text { Teach \& prompt occurrence of replace } \\
\text { behaviors; providing compartment to } \\
\text { materials; checklist addressing beha } \\
\text { goals; positive reinforcement }\end{array}$ \\
\hline $\begin{array}{l}\text { 12. Lane, Smither } \\
\text { et al. }(2007)\end{array}$ & $\begin{array}{l}\text { Hitting or kicking peers; } \\
\text { noncompliance; out of seat; talking to } \\
\text { peers; making faces; touching objects }\end{array}$ & $\begin{array}{l}\text { Self-monitoring; differential reinforcement; } \\
\text { positive scanning (e.g., positive teacher note to } \\
\text { student) }\end{array}$ \\
\hline $\begin{array}{l}\text { Lane, } \\
\text { Weisenbach et } \\
\text { al. (2007) }\end{array}$ & $\begin{array}{l}\text { Talking to peers; making negative } \\
\text { statements; rolling eyes; out of } \\
\text { assigned area; blurting out }\end{array}$ & $\begin{array}{l}\text { Replacement behavior training; changing } \\
\text { seating arrangement; prompt cards; contingent } \\
\text { reinforcement; altered contingencies; DNRA. }\end{array}$ \\
\hline $\begin{array}{l}\text { 14. LeGray et al. } \\
(2010)\end{array}$ & Inapp & $\begin{array}{l}\text { Differential reinforcement of other behavior } \\
\text { (DRO); differential reinforcement of a } \\
\text { functional alternative (DRA) }\end{array}$ \\
\hline $\begin{array}{l}\text { 15. Lewis \& Sugai } \\
\text { (1996) }\end{array}$ & $\begin{array}{l}\text { Walking around; playing with peers } \\
\text { during lessons; refusal to follow } \\
\text { teacher directions }\end{array}$ & $\begin{array}{l}\text { Requiring participant to remain on-task longer } \\
\text { periods of time using DRI, DRI + peer } \\
\text { attention; peer tutoring }\end{array}$ \\
\hline $\begin{array}{l}\text { 16. Moore et al. } \\
(2005)\end{array}$ & $\begin{array}{l}\text { Looking around the room; failure to } \\
\text { follow teacher directions; giggling; } \\
\text { talking; out of seat; touching others }\end{array}$ & $\begin{array}{l}\text { Reducing task duration; modifying assignments } \\
\text { (e.g., } 3 \text { worksheets of } 5 \text { problems instead of } 1 \\
\text { worksheet of } 15 \text { problems) }\end{array}$ \\
\hline $\begin{array}{l}\text { 17. Newcomer \& } \\
\text { Lewis (2004) }\end{array}$ & 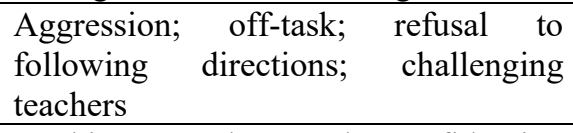 & $\begin{array}{l}\text { nent; extinction; change } \\
\text { antecedents }\end{array}$ \\
\hline $\begin{array}{l}\text { 18. Packenham } \\
\text { al. (2004) }\end{array}$ & $\begin{array}{l}\text { Looking at other students; fidgeting } \\
\text { with objects, talking to peers, out of } \\
\text { seat, laughing }\end{array}$ & $\begin{array}{l}\text { Contingent teacher attention for appropriate } \\
\text { behavior; teacher spent } 1-2 \text { min. talking with } \\
\text { student; provide explicit instructions; shorten } \\
\text { lessons; positive reinforcement }\end{array}$ \\
\hline
\end{tabular}




\begin{tabular}{|c|c|c|}
\hline Study & Dependent variables & Intervention \\
\hline $\begin{array}{ll}19 . & \text { Patterson } \\
(2009) & \\
\end{array}$ & Out of seat walking around the room & $\begin{array}{l}\text { Teacher spending } 2 \text { min. talking with student } \\
\text { prior to lesson }\end{array}$ \\
\hline $\begin{array}{l}\text { 20. Payne et al. } \\
(2007)\end{array}$ & $\begin{array}{l}\text { Talking or gesturing to peer; looking } \\
\text { away from teacher or academic } \\
\text { materials; refusal to following } \\
\text { directions; manipulating objects }\end{array}$ & $\begin{array}{l}\text { Negative reinforcement (e.g., earn a break for } \\
\text { task completion); spend time with a peer } \\
\text { contingent on task completion; contingent } \\
\text { reinforcement }\end{array}$ \\
\hline $\begin{array}{l}\text { 21. Sanford \& } \\
\text { Horner }(2012)\end{array}$ & $\begin{array}{l}\text { Talking out; out of seat; playing with } \\
\text { objects; refusing to follow directions; } \\
\text { hair pulling }\end{array}$ & Instruction-level reading placement \\
\hline $\begin{array}{c}\text { 22. Shumate \& } \\
\text { Wills }(2010)\end{array}$ & $\begin{array}{l}\text { Arguing, taunting, name calling, \& } \\
\text { singing; pencil tapping; talking to } \\
\text { peers; out of seat }\end{array}$ & $\mathrm{DRC}$ \\
\hline 23. Storey et al. & $\begin{array}{l}\text { Talking out; touching others; throwing } \\
\text { objects; taunting peers }\end{array}$ & $\begin{array}{l}\text { Contingent teacher attention for appropriate } \\
\text { behavior; self-monitoring }\end{array}$ \\
\hline $\begin{array}{l}\text { 24. Trussell et al. } \\
(2016)\end{array}$ & $\begin{array}{l}\text { Talking \& blurting out; throwing } \\
\text { objects; hitting peers; playing with } \\
\text { objects; crying; sexually explicit } \\
\text { language }\end{array}$ & $\begin{array}{l}\text { Teaching replacement behaviors; social skills } \\
\text { training; contingent attention; ignore student for } \\
\text { inappropriate behavior; repositioning desks; } \\
\text { providing breaks }\end{array}$ \\
\hline
\end{tabular}

